
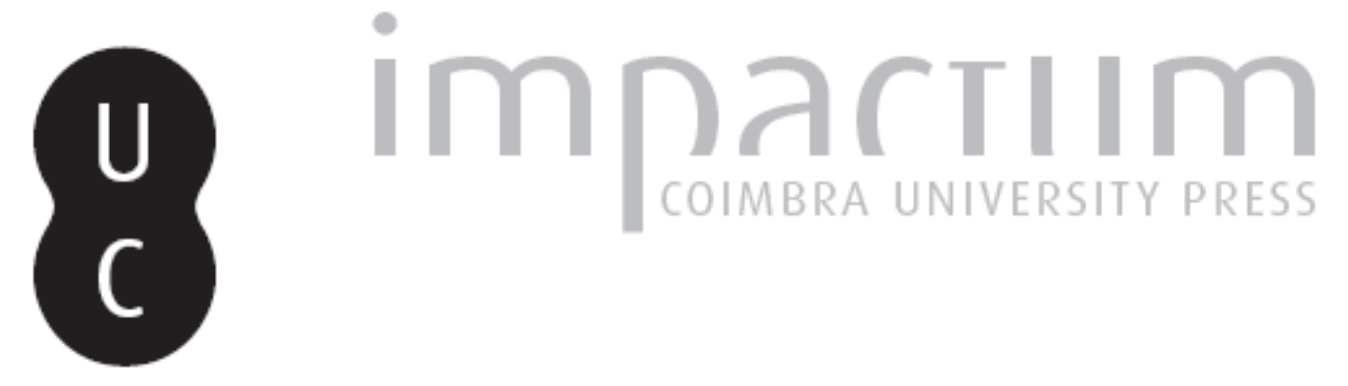

\title{
A história na obra de Eudoro de Sousa
}

\section{Autor(es): $\quad$ Cairus, Henrique}

Publicado por: Annablume Clássica; Imprensa da Universidade de Coimbra

URL persistente:

URI:http://hdl.handle.net/10316.2/24344

DOI:

DOI:http://dx.doi.org/10.14195/1984-249X_8_8

Accessed : $\quad$ 26-Apr-2023 12:25:37

A navegação consulta e descarregamento dos títulos inseridos nas Bibliotecas Digitais UC Digitalis, UC Pombalina e UC Impactum, pressupõem a aceitação plena e sem reservas dos Termos e Condições de Uso destas Bibliotecas Digitais, disponíveis em https://digitalis.uc.pt/pt-pt/termos.

Conforme exposto nos referidos Termos e Condições de Uso, o descarregamento de títulos de acesso restrito requer uma licença válida de autorização devendo o utilizador aceder ao(s) documento(s) a partir de um endereço de IP da instituição detentora da supramencionada licença.

Ao utilizador é apenas permitido o descarregamento para uso pessoal, pelo que o emprego do(s) título(s) descarregado(s) para outro fim, designadamente comercial, carece de autorização do respetivo autor ou editor da obra.

Na medida em que todas as obras da UC Digitalis se encontram protegidas pelo Código do Direito de Autor e Direitos Conexos e demais legislação aplicável, toda a cópia, parcial ou total, deste documento, nos casos em que é legalmente admitida, deverá conter ou fazer-se acompanhar por este aviso. 
jan.2012

issn $2179-4960$

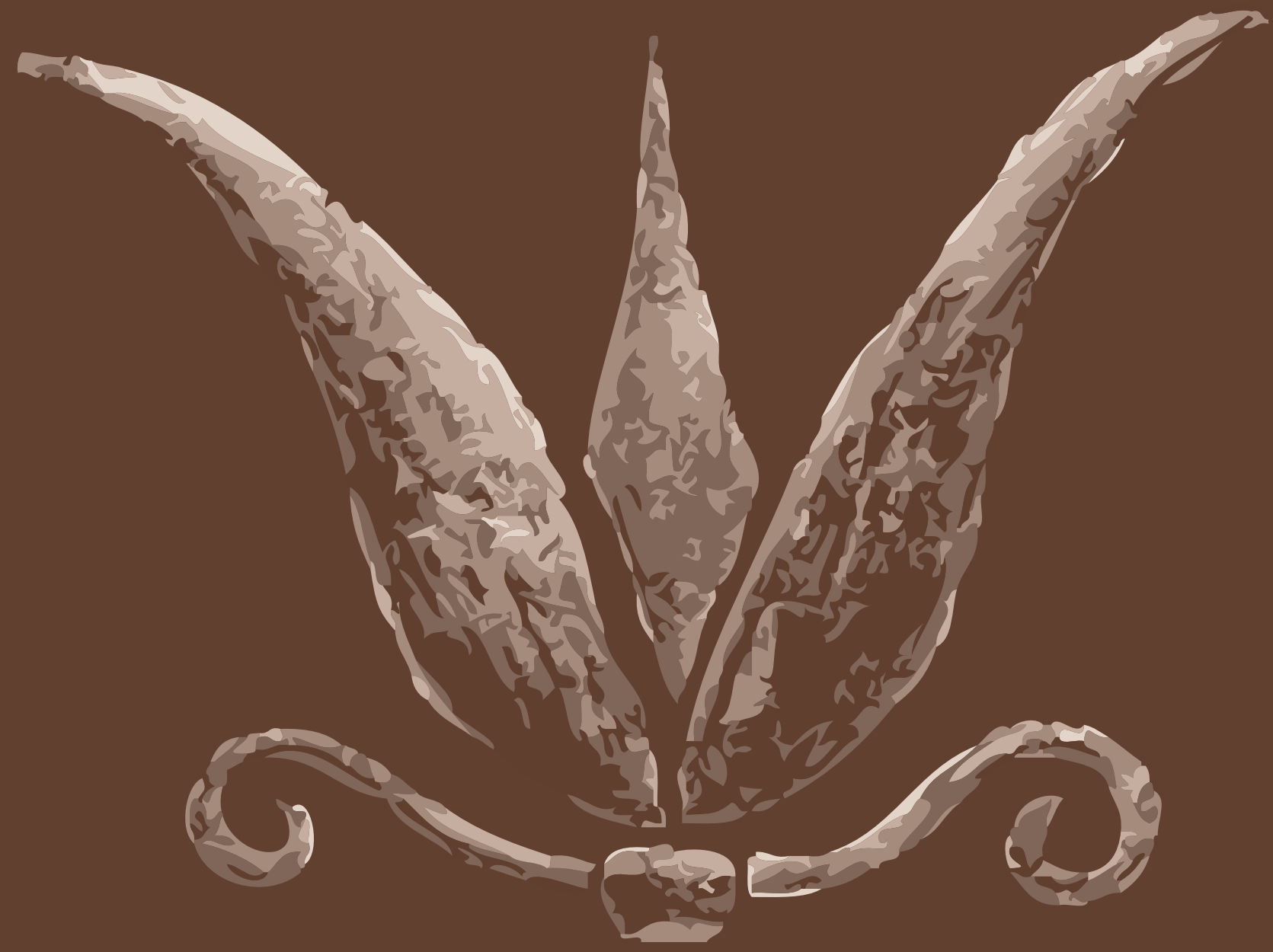

R E V I S T A
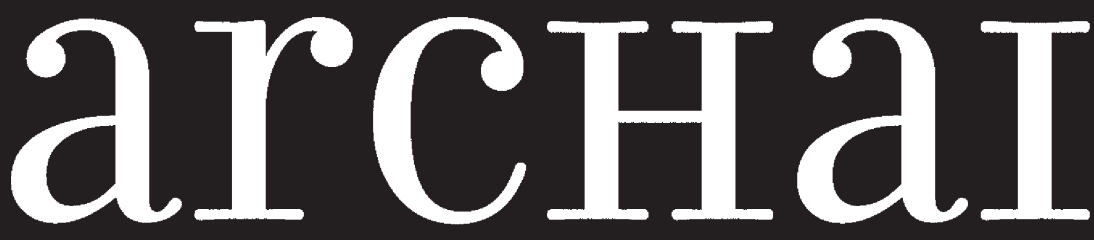

AS ORIGENS DO PENSAMENTO OCIDENTAL

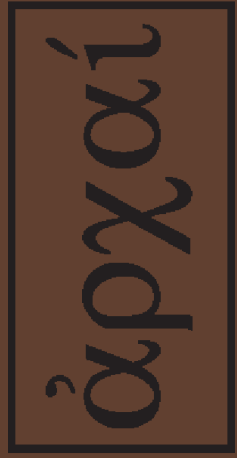

ARCHAI JOURNAL: ON THE ORIGINS OF WESTERN THOUGHT
arcHaI

AS ORIGENS DO PENSAMENTO OCIDENTA.

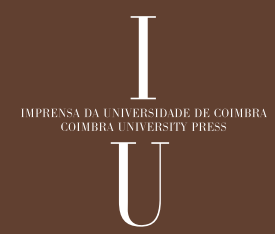

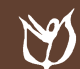




\section{A HISTÓRIA NA OBRA DE EUDORO DE SOUSA}

CAIRUS, H. (2012). "A História na obra de Eudoro de Sousa". Archai n. 8, jan-jun 2012, pp. 81-86.

RESUMO: 0 presente texto tem por objetivo apontar caminhos para o estudo do conceito de história na obra de Eudoro de Sousa, especialmente no seu livro História e mito. Para acompanhar seu pensamento acerca da historicidade e da temporalidade, procurou-se sugerir aqui uma interpretação também de seu percurso de formação e de suas possiveis influências.

PALAVRAS-CHAVE: Eudoro de Sousa, historicidade, temporalidade, história em Eudoro de Sousa

ABSTRACT: This paper aims to point out possible ways to study the concept of History in Eudoro de Sousa's works, especially in "History and Myth". In order to follow Eudoro de Sousa's thoughts concerning historicity and temporality, it is therefore suggested an interpretation of his educational background and what might have possibly influenced his thoughts.

KEYWORDS: Eudoro de Sousa, historicity, temporality, History in Eudoro de Sousa
* Universidade Federal do Rio de Janeiro.

\section{Henrique Cairus *}

Nosso desejo de Ocidente levou-nos muitas vezes à Europa. Em muitas ocasiões, a Europa aproxima-se deste Novo Mundo para contribuir com seu projeto de inserção no Ocidente. Projeto, de resto, muito bem sucedido, que se inscreve em outro muito maior, que tem um marco fundamental do qual os 200 anos comemoramos agora.

Em vários lugares do Brasil, lugares que respondiam, em certo momento, ao apelo de haver, no Brasil, centros difusores dessa cultura que nos inscrevia no 0cidente recebiam o apoio quase missionário de grandes representantes da cultura identitária do chamado "Velho Mundo", a cultura clássica.

Para falar especificamente dos luminares europeus que aqui pousaram para atuar na área de grego, podemos destacar o Prof. Aubreton, discípulo direto do Prof. Paul Mazon, francês, que atuou na USP; o Prof. Frei Damião Berge, OFM, alemão, que constituiu o primeiro núcleo de estudos helênicos na UFRJ, então Universidade do Brasil, além de alguns outros com os quais serei injusto por não os mencionar.

É nesse contexto que quero laudar, ainda que insuficientemente, nosso homenageado desta mesa, o grande luso-brasileiro, lisboeta-brasiliense, Professor Eudoro de Sousa. Exemplo de intelectual 
que colocou sua vida a serviço do saber universitário, plantando, por onde passasse, sementes que germinaram e frutificaram. Coube-nos, assim, a felicidade de tê-lo entre os primeiros docentes desta Universidade.

A fundação do Centro de Estudos Clássicos da UnB, fruto do trabalho incansável e agregador do Professor Eudoro, reeditou e ampliou, na década de 60, seu sucesso de dez anos antes, em Santa Catarina, onde contribuiu decisivamente para 0 nascimento da Faculdade de Filosofia de Santa Catarina, durante o governo de Heriberto Hülse. Tudo isso num tempo em que os intelectuais realmente grandes não consideravam menores as tarefas administrativas, e não usavam, para furtarem-se delas, de subterfúgios, como reduzir à burocracia infundada qualquer empreendimento que tenha por fim a melhoria da instituição onde empenham suas vidas, às vezes, por inteiro.

A História, muito graças à obra da Professora Constança Marcondes Cesar, ligou a sua passagem por São Paulo, onde atuou na USP, na PUC e na Unicamp à formação do chamado "Grupo de São Paulo", responsável pela Revista "Diálogo" em que participaram também seu compatriota, Agostinho da Silva, e os brasileiros Vicente e Dora Ferreira da Silva e Miguel Reale.

Não seria pouco se o laureado helenista Eudoro de Sousa houvesse erigido este Centro de Estudos Clássicos, que, de certa forma, o Archai continua. Mas seu legado estendeu-se ao campo bibliográfico. E, quando desembarcou, em 1966, em nosso País, que doravante seria também dele, já trazia na bagagem a primeira versão de sua tradução da Poética de Aristóteles, publicada quinze anos antes em Portugal. Durante muitos anos essa foi uma das duas únicas versões da Poética ${ }^{1}$ traduzida ao vernáculo diretamente do grego, e até 2004 continuou sendo a única ao alcance do leitor comum. E foi aqui, no Brasil, mais especificamente em Brasília, que produziu e publicou, em 1974, sua tradução das Bacantes, além de várias outras obras.

Trazia também às costas brasileiras uma formação que fazia ressoar aqui as cordas da Escola Portuense, em tudo que isso significava. É evidente que, naquele momento, em seu espírito, fervilhava o interesse pelo simbólico e pela religião grega; um talvez inspirado pelo seu contato com Almada Negreiros e Sant'Ana Dionísio, e outro, pelo convívio com Agostinho da Silva (LÓIA, 2007). Sua passagem pela Universidade de Heidelberg, para a qual fora indicado por Delfim Santos para ocupar a vaga de Leitor de Língua Portuguesa, deu-lhe oportunidade de afinar-se com a maneira germânica de ver a Antiguidade helênica, maneira essa que ainda hoje é tônica, embora não exclusiva, nos estudos universitários portugueses, em que um sólido e erudito aparato filológico e arqueológico é colocado à disposição de questões que vão para muito além do tempo. No entanto, Eudoro de Sousa exigia do universo acadêmico português ainda maior proximidade do pensamento alemão. É com esse espírito e com sua verve contundente que publicou 0 artigo "A incapacidade especulativa dos portugueses", mais tarde reunido no volume Origem da poesia e da mitologia, organizado por Joaquim Domingues.

0 tema desta minha fala que busca homenagear o Prof. Eudoro de Sousa consiste numa tentativa de praticar o que the foi tão caro: o diálogo. E meu ponto de partida para esse diálogo será uma obra publicada pela própria UnB em 1988, um ano depois do falecimento do autor, e que recebeu, por desígnio do próprio autor o título de Mitologia II (História e mito), conforme explica Fernando Bastos, na apresentação da obra.

Essa obra ensaística de Eudoro de Sousa tem um formato sui generis. Em parágrafos numerados, à moda das edições dos textos antigos, de escrita densa, bom vernáculo, sem adornos, o autor não poupa fôlego em cada tema a que se dedica. Cada um desses parágrafos começa com uma assertiva introdutória de caráter contundente, que o resto do parágrafo parece glosar. Ao contrário de Dioniso em Creta, por exemplo, Mitologia quase não apresenta citações, referências ou remissões. Seu texto parece ser formado em sucessivas espirais de diâmetro crescente, onde um axioma vai sendo dilatado a ponto de, ao fim de cada longo parágrafo, mostrar toda a força que nele estava concentrada.

0 parágrafo 12 , por exemplo, que nos interessa especialmente, tem por início o axioma: “não posso conceder à história". É uma colocação
1. Rivalizando vantajosamente com a tradução de Jaime Bruna. 
em primeira pessoa que, isolada, assim, pareceria destoar de um Eudoro de Sousa que entrou para a história dos estudos literários precisamente como um helenista que olhava de frente para o tempo.

Foi esse desencontro entre sentenças como essa e o conjunto do pensamento de Eudoro de Sousa que despertou a questão que move esta minha fala: 0 que é, para Eudoro de Sousa, a história, essa história que ele nega e pratica? Pareceu-me realmente uma tarefa importante, por tratar-se de Eudodo de Sousa, saber como um estudioso que lida com o passado pretende "não conceder à história".

"Uma sucessão de épocas", afirma o nosso helenista homenageado, "não assinala uma linha de progresso (nem de regresso), mas tão-somente as singularidades caleidoscópicas de antigos-distantes, polarmente associados a atuais-próximos, atuais e antigos que definem, por sua vez, as singularidades das épocas".

Eis uma proposição que, em nossa imagem aqui proposta, seria a segunda volta do espiral de sua urdidura discursiva. Pode-se facilmente inferir dessa colocação que sua visão de História postula uma definição para essa disciplina onde ela equivale a uma sucessão de épocas a partir do fio condutor do progresso ou do regresso. Sua posição em relação a essa disciplina, todos conviríamos, não está muito distante do que dizemos e pensamos de certos discursos historiográficos que se apoiam precisamente sobre os pilares do progresso ou do regresso. Também podemos fazer-lhe coro, e dizer que também nós não concedemos a ela.

Essa "segunda volta de seu espiral discursivo" provoca nossa adesão hoje, ainda que possamos ressalvar que não é essa a nossa ideia de história, mas a ideia que façamos de história seguramente não granjeava, nas décadas de 60 e 70, a simpatia da cátedra brasileira, ainda majoritariamente comprometida com uma perspectiva positivista; progressista, mais que regressista, da história.

É difícil para um estudante de humanidades, especialmente para um estudante de História, imaginar que, há tão pouco tempo, as nossas universidades, hoje tão na vanguarda dos estudos historiográficos, ainda resistiam aos primeiros ecos vindos da França, onde se sistematizavam as reações ao positivismo histórico. Por aqui, como sabemos todos, a tensão entre o antigo e o novo ficou cindida pelos limites das posições ideológicas polarizadas. Mas a mente inquieta de Eudoro de Sousa não se permitiu esses limites nos quais percebia as mesmas reduções que the incomodavam na visão que merecia o título de positivista; em especial a perspectiva progressista do processo histórico.

A presença da ideia de "sucessão de épocas" é frequente nos manuais de História, mesmo nos manuais de história literária ou filosófica. Esse problema, mesmo reduzido, ainda persiste. Nossos manuais escolares e mesmo universitários não oferecem, por exemplo, nenhuma informação sobre qualquer outra parte do mundo, durante as Guerras Púnicas, a não ser, é claro, que a notícia tenha alguma relação com essas próprias Guerras. Essa sucessão de épocas, que descarta a simultaneidade, e, por conseguinte a diferença, parece receber, nas perspectivas históricas que Eudoro de Sousa tão bem identificou, o acréscimo de vetores de progresso e de regresso.

A resposta de Eudoro de Sousa para essa configuração do pensamento historiográfico foi implacável, e, como não poderia deixar de ser, ao responder, apresenta a sua proposta para a história, à qual chegarei em breve.

Ao progresso e ao regresso, Eudoro de Sousa retruca: "de uma época para outra, não avançamos: diversificamo-nos". Seguindo o pensamento de nosso homenageado, diversificamo-nos no eixo temporal. Por meio dessa diversidade, distanciamo-nos do "passado-lonjura" ou do "passado-outrora". Tornamo-nos diferentes desse "passado-outrora" por meio de uma distância da qual não podemos nos livrar.

Eudoro de Sousa fala fundamentalmente de três práticas historiográficas: a positivista progressista, a regressista (estas primeiras com seus fundamentos bem fincados no séc. XIX), a positivista cientificista e a ideologicamente polarizada pelos "nacionalismos de direita ou de esquerda".

Pode essa minha honrosa audiência contra- argumentar que ficaram excluídas do raio de visão de Eudoro de Sousa as ideias propagadas pelos autores dos Annales, bem como as propostas dos teóricos da Nova História. Talvez Eudoro de Sousa 
tivesse se encantado com o pensamento radical de Hayden White ou com a renovação de Lynn Hunt. Mas Eudoro de Sousa não viveu este nosso momento, em que olhamos com a tranquilidade da distância para o campo de marte onde a hegemonia positivista e suas variantes foram derrubadas do trono no pensamento historiográfico. Eudoro de Sousa não pode ter essa nossa tranquilidade e, para ser o que foi, nem poderia ter o discurso esterilizado e, não raro, estéril que praticamos nós; nós que já inscrevemos na própria história remota toda a historiografia que Eudoro de Sousa chamava simplesmente de "História", e à qual ele não admitia fazer qualquer concessão.

É a essa História que Eudoro de Sousa não consente; é essa a História que ele repele: a mesma que hoje estudamos como um fato remoto e um risco do qual estamos aparentemente livres, mesmo sabendo que nada impediria a sua volta senão um frágil consenso de que esse caminho está superado. Mas, diferentemente de nós, nestes nossos tempos, para Eudoro de Sousa, este era todo o horizonte do fazer historiográfico. Portanto, esse horizonte encerrava a própria história em todas as suas possibilidades. Era pouco, é verdade, mas era o que havia. E nem mesmo uma imaginação como a de Eudoro de Sousa poderia imaginar que a verdadeira revolução intelectual do século XX eclodiria do ventre desse campo do saber que há tão pouco tempo não era mais do que um depositário de dados.

Toda essa reflexão, no entanto, está a serviço de uma exigência, como diz o próprio homenageado (1988:14), um pacto pelo qual ele poderia ser compreendido. Esse pacto com o leitor consiste em acertar que o discurso historiográfico é uma construção de um imaginário específico. Nas palavras de Eudoro de Sousa:

Só temos de evitar um escolho em que, inevitavelmente, fatalmente naufragaríamos: é o da reivindicação da verdade absoluta e exclusiva para a verdade histórica de uma só figuração do antigo. A Grécia antiga não se esgota na imagem do Renascimento, do Iluminismo, do Romantismo e do Neo-humanismo. Nem qualquer delas, nem em todas elas.

Esse viveiro de questões em que entramos agora pelas mãos de Eudoro de Sousa nos tenta a impor-lhe os parâmetros de que nos valemos quase que automaticamente, e desde a difusão das ideias dos pioneiros dos Annales, para pensarmos conceitos como 'verdade histórica' ou mesmo 'imaginário específico'. Quero, contudo, convidar minha audiência para vencer essa tentação, e pensar com a generosidade que devemos ter para com aqueles que abrem, em plena selva, as trilhas que viram as estradas pelas quais transitamos com segurança.

Se digo isso é porque a 'verdade absoluta e exclusiva' é um ponto delicado para o pensamento historiográfico, que, conquanto a tenha deslocado, ora para o 'imaginário' ora para o 'dado' ou ainda para ambos simultaneamente, não a nega em momento algum, como faz frequentemente a filosofia - especialmente a contemporânea - e como faz, em vários momentos, o próprio Eudoro de Sousa.

0 próximo ponto de debate que a impiedosa pena de Eudoro de Sousa nos propõe, ela mesma, é o problema do anacronismo.

Foi preciso esperar que o ensaio de Nicole Loraux, "0 elogio do anacronismo na história", ressoasse pelo mundo, para ter-se mais clareza sobre a magnitude da questão que inquietou Eudoro de Sousa.

Diz Eudoro de Sousa: “0 historiador de uma época não pode sair dela, e, perseguindo metodicamente os vestígios da antiguidade, vai ao encontro de uma, já predeterminada pelo seu presente: um antigo que é só atualidade atenuada do que já atual se fez, na sua atualidade"(1988, p.15).

Para Eudoro de Sousa, esse anacronismo inerente ao ofício do historiador parece inviabilizar a História como projeto, se a ela continuar-se a dar o sentido que até então tivera.

A reconciliação da História com o anacronismo, que talvez seja o maior dos limites para o seu grande projeto, ficou a cargo do famoso artigo de Nicole Loraux, não por acaso uma helenista, como Eudoro de Sousa.

Talvez inspirada pelas reflexões de Walter Benjamin sobre a história, Nicole Loraux, em seu "Elogio do anacronismo", publicado no Brasil em 1992, declara que o "anacronismo se impõe a partir do momento que, para um historiador da Antiguidade, o presente é o mais eficaz dos motores do impulso de 
compreender" (LORAUX, 1992, p. 58). E essa não é outra senão a postura do nosso homenageado. É uma manifestação de uma inquietude de espírito digna de nota. Como conciliar a História, tal qual ele a entendia, com a necessidade do "motor" do anacronismo?

“0 anacronismo é o pesadelo do historiador, o pecado capital contra o método", escreve Nicole Loraux (loc.cit.). Eudoro de Sousa, por sua vez, evoca a imagem de um círculo, onde o que ele chama de "passado-lonjura" encontrar-se-ia com a antiguidade-distante. Esse ideal, para ele, não pode ser atingido pelo pensamento histórico, ou, pelo menos, pelo que ele reconhece como pensamento histórico, mas exige, seguindo sua imagem e seu pensamento, um compasso que trace essa circunferência, e esse compasso traz novamente 0 problema do anacronismo. Pois, segundo o nosso autor, um compasso precisa de um centro onde deve ser fincado, e esse centro não pode ser outro que não a atualidade. Para Eudoro de Sousa, a antiguidade-distante apenas dista, mas não se afasta do centro do compasso, ou seja, da atualidade. Mas o problema da historicidade retorna: "nenhuma concentração de presentes epocais", no dizer de Eudoro de Sousa, “pode representar o centro", pois, "só no ponto equidistante dos dois pontos que marcam o início e o término de uma época se poderia fixar um centro; mas quem, no interior de qualquer época, sabe onde ela principia e acaba?" (1988, p.17-8) .

Ficaria faltando aí, para o leitor, nosso contemporâneo, a definição de época e dessa História que "não sabe onde historicamente começa e onde historicamente termina". Mas podemos dizer que, para ele, a História persegue "para trás e para frente" (?) "a presença do presente". Pois, para a História, segundo Eudoro de Sousa, "não há passado, mas só a atenuada presença do presente".

Esse raciocínio pode parecer privilegiar o anacronismo, mas, como dissemos, o anacronismo inerente ao pensamento histórico, para Eudoro de Sousa, inviabilizaria o próprio pensamento histórico como rumo. Inviabilizaria, se não fosse um outro caminho ao qual já iremos chegar. Cabe, porém, antes, tentar buscar as raízes desse dizer tão radical de Eudoro de Sousa.

Benedetto Croce, autor tão presente na formação intelectual de Eudoro de Sousa quanto
Toynbee, desafinou o coro dos pensadores de sua época, ao propor que a "paixão" do historiador é termo necessariamente constitutivo do discurso historiográfico. Em $A$ história como pensamento $e$ como ação, Croce enuncia seu famoso axioma que patrocina toda a discussão que Eudoro de Sousa empreende: “A cultura histórica tem o objetivo de manter viva a consciência que a sociedade humana tem do próprio passado, ou melhor, do seu presente, ou melhor, de si mesma" (2006[1938], p. 86). 0 que não se distancia muito do que Gadamer, outra leitura cara a Eudoro de Sousa, afirma quando diz, em sua obra 0 problema da consciência histórica:

A consciência histórica que hoje temos de história difere fundamentalmente do modo pelo qual anteriormente o passado se apresentava a um povo ou a uma época. Entendemos por consciência histórica o privilégio do homem moderno de ter plena consciência da historicidade de todo presente e da relatividade de toda opinião. $(2006, p .17)$

0 anacronismo é tão minuciosamente trabaIhado na obra de Eudoro de Sousa, que seria impossível lembrar de todos os conceitos e categorias que o nosso homenageado cria ou redimensiona, para dar conta desse problema que preocupa não só a ele, mas a todos nós, que lidamos com esse passado-lonjura, que, para ele, era tão melhor quanto menos se confundisse com a antiguidade-distante.

Finalmente, e aqui chegamos perto do ponto final, que será colocado prematuramente nesse discurso, em nome da preservação dos ouvidos ou olhos alheios, tratemos de dois pontos que Eudoro de Sousa vai relacionar com a História, para, assim, solidificar sua proposta para uma leitura do passado: a origem e o mito.

É uma das atribuições das mentes privilegiadas apontar o óbvio, ou, se preferirmos, dar ao velado a feição do óbvio. Assim ocorre quando lemos um Eudoro de Sousa a lembrar-nos de que a origem é um ponto arbitrário:

Não preciso lembrar que, em certo ponto da escala temporal, o historiador da cultura brasileira teria de enfrentar a cultura ibérica, e daí partir para a cultura 
europeia, e que, no estado atual dos nossos conhecimentos, só nos deteríamos no berço desta última, situado no mediterrâneo oriental pré-helênico, nas culturas neolíticas pré-cerâmicas da Ásia Menor. Não preciso lembrar, porque todos o sabem, como, por outro lado, por via da caricatura, não há o onde determo-nos. (1988:15-6)

A origem, no entanto, mesmo que arbitrária, é um conceito fundamental na obra de Eudoro de Sousa. E não poderia ser muito diferente, quando se trata de um helenista que acredita que a Grécia é uma origem. Mas é preciso sempre dizer de quê.

A ideia de origem, que Marc Bloch tomou como um dos alvos de suas críticas, só é possível diante de um referencial que, se não está explícito nos escritos de Eudoro, também não está oculto. Há, de fato, uma crença em certa permanência ou perenidade que perpassa a história, em que, segundo Eudoro de Sousa, "a polaridade antigo-atual está a ponto de romper-se, a lonjura e o outrora absorverão a distância, uma e outra podem rolar pelo pendor da encosta extrema e destruir a atualidade de bens culturais que mais a peito nos propusemos a defender".

A História, para Eudoro de Sousa, é a história do mesmo homem, um homem que tem uma perenidade assegurada pela natureza. Não deixa de ser o que Newton Bignoto (1996) e Helena Mollo (2001) chamaram de "o círculo e a linha", que não deixam de ser também as dimensões da história de Eudoro de Sousa, como integraram, em outra medida, a compreensão de tempo dos próprios gregos, que Eudoro de Sousa tanto estudou. Há um "sub" no "pré", uma "subistória" no lugar de uma "história", uma permanência na origem, em forma de um substrato.

0 projeto de Eudoro de Sousa para a história parte da consciência da fragilidade da epocalidade, para pensar em certa essência temporal, ela própria com alto grau de atemporalidade. Essa fragilidade da história não o leva a rejeitá-la. Para Eudoro de Sousa, "a história é feita pela investigação dos vestígios", e, se os vestígios a fragilizam, a consciência de que ela é feita pela investigação a robustece como campo do saber. E esse campo do saber, para Eudoro de Sousa, deve conduzir-nos para além do tempo.

Esse além do tempo, Eudoro de Sousa o situa no "mítico". Esse mítico que, segundo nosso homenageado, “está antes de todo o curso da história, desde o início até o término".

Mas encerro aqui minha fala, que já se estendeu demais. Não, porém, sem antes dizer que foi justamente essa seara em que doravante adentraríamos que fez de Eudoro de Sousa o helenista lusófono mais célebre: a investigação sobre o mito, em especial, sua teoria sobre o mítico que antecede o alegórico, tão diversamente do que se dizia até então, ao menos em nossa língua. Por isso, vale a pena encerrar esta fala com um famoso aforismo seu:

A pré-história é o sempre 'antes' da história; o passado é o sempre 'antes' do presente; a lonjura é o sempre 'antes' da distância; o outrora é o sempre 'antes' de qualquer agora; a sensibilidade é o sempre 'antes' da inteligibilidade; a natureza é o sempre 'antes' do natural (e do sobrenatural); o mítico é o sempre 'antes' do alegórico. Mas sem antes não há depois. (1988:61)

\section{REFERÊNCIAS BIBLIOGRÁFICAS}

BASTOS, Fernando (1992). Mito e filosofia: Eudoro de Sousa e a complementaridade do horizonte (sobre uma Ontoantropologia). Brasília, Ed.UnB.

BIGNOTTO, Newton (1996). 0 círculo e a linha. In: NOVAES, Adauto (org.) Tempo e História. 2a- ed. São Paulo, Secretaria Municipal de Cultura / Companhia das Letras.

CESAR, Constança Terezinha Marcondes (2004). A filomitia de Eudoro de Sousa. In. SOUSA, Eudoro de. Mitologia: Historia e Mito. Lisboa, Imprensa Nacional - Casa da Moeda.

CROCE, Bebedetto (2006). História como história da liberdade. Trad. Júlio Castañon Guimarães. Rio de Janeiro, Topbooks.

GADAMER, Hans-Georg (2006). 0 problema da consciência histórica. Rio de Janeiro, FGV.

LóIA, Luís (2007). 0 essencial sobre Eudoro de Sousa. Lisboa, Imprensa Nacional - Casa da Moeda.

MOLLO, Helena Miranda (2001). 0 círculo e a linha: o conceito de tempo em Eurípides. Tese de Doutorado. Rio de Janeiro, Faculdade de Letras da UFRJ.

SOUSA, Eudoro de (1973). Dioniso em Creta e Outros Ensaios: estudos de mitologia e filosofia da Grécia Antiga. São Paulo, Duas Cidades.

Ed.UnB.

(1988). Mitologia II: História e mito. Brasília,

(2000). Origem da poesia e da mitologia e outros ensaios dispersos. Org. Joaquim Domingues. Lisboa: Imprensa Nacional - Casa da Moeda. 